\title{
Dynamic Characteristics Analysis on Wind-Blown Sand Ground under Dynamic Compaction Vibration
}

\author{
Jihui Ding1* , Jinguo Liang2, Wei Wang2 \\ ${ }^{1}$ College of Civil Engineering, Hebei University, Baoding, China \\ ${ }^{2}$ Ltd. of Research Institute of Construction \& Investigation of Hebei, Shijiazhuang, China \\ Email: ${ }^{*}$ dingjihui@126.com
}

Received 20 April 2014; revised 31 May 2014; accepted 19 June 2014

Copyright (C) 2014 by authors and Scientific Research Publishing Inc.

This work is licensed under the Creative Commons Attribution International License (CC BY). http://creativecommons.org/licenses/by/4.0/

(c) (i) Open Access

\section{Abstract}

In the $6000 \mathrm{kN} \cdot \mathrm{m}$ energy level dynamic compaction on Inner Mongolia wind-blown sand foundation treatment process, the dynamic characteristics and dynamic response are measured. Vibration action time, vibration main frequency, peak acceleration and peak velocity are analyzed. The vibration acting time is very short, the vertical average vibration acting time increases obviously with distance increasing, and the horizontal average vibration time does hardly change. The main frequency of vibration is at $4.60-24.90 \mathrm{~Hz}$, which depends on the soil properties and soil layer distribution. The peak acceleration and peak velocity space distribution are similar. The maximum of horizontal acceleration peak is close to vertical velocity peak, and is near to $\mathbf{5 1} \mathrm{g}$ under rammer. The maximum of horizontal velocity peak is close to vertical velocity peak, and is near to $54 \mathrm{~m} / \mathrm{s}$ under rammer. The peak acceleration and velocity are rapidly attenuated, but the vertical peak acceleration and peak velocity are slowly attenuated than horizontal direction. The effective treating depth arrives $13 \mathrm{~m}$ for wind-blown wind, peak acceleration is $1.8 \mathrm{~g}$ or so, and peak velocity is $2.1 \mathrm{~m} / \mathrm{s}$ or so. Horizontal treating range is 2.6 times of rammer diameter, and vertical treating range is 5.65 times of rammer diameter.

\section{Keywords}

Wind-Blown Sand Ground, Dynamic Compaction, Vibration Effects, Dynamic Characteristics, Field Experiment

\footnotetext{
*Corresponding author.
}

How to cite this paper: Ding, J.H., Liang, J.G. and Wang, W. (2014) Dynamic Characteristics Analysis on Wind-Blown Sand Ground under Dynamic Compaction Vibration. World Journal of Engineering and Technology, 2, 171-178. 


\section{Introduction}

Dynamic compaction method is used for the huge compaction hammer to bring shock wave and dynamic stress in the ground and make it compact. So far, dynamic compaction method has been successfully and widely used to deal with all kinds of gravel soil silt, sandy soil, collapsible loess, artificial fill, low saturation and clay, especially the large gravel soil and municipal solid waste or industrial waste composition complex fill, which is difficult to reinforce and construct with the general method. Dynamic compaction has been widely applied to treat various ground foundation, but there is not mature and perfect design theory up to now. The treating effects and treating range of dynamic compaction were based on soil's consolidation theory and wave compression theory. The treating effect is detected by using a standard penetration test, static load test, and the indoor experiment.

Aeolian sand is widely distributed in the surface of plateau and desert area, and the bearing capacity and deformation characteristics of the sand foundation are not made systematic theoretical research [1]. High pressure jet grouting pile and sand cushion reinforcement method was used by Aeolian sand foundation treatment [2], but not suitable for large area processing. In recent years, the engineering practice in desert area proves that dynamic compaction of Aeolian sand is economical and practical [3]. The Aeolian sand foundation is treated by the compaction method in hinterland of the desert, which solves the problem of uneven settlement of Aeolian desert oil exploration rig foundation [4]. The treating effect and its factors are accord with practice by using dynamic measuring [5]-[7]. Based on the engineering background of the project treated by dynamic compaction in Inner Mongolia, through the analysis of dynamic measuring, the dynamic characteristics and dynamic response are studied.

\section{The General Situation of Project}

\subsection{Geological Condition of Project}

The treating wind-blown sand project used by dynamic compaction is in Inner Mongolia, According to the supper structure load requirement, the bearing capacity of reinforcement is not smaller than $250 \mathrm{kPa}$, and deformation modulus is 7.0 Mpa. The soil distribution of site is as follows.

Element layer (1) - backfill sand: The soil strength is low and deformation modulus is high, engineering properties are instable, expanding property caused by freezing belongs to medium, the thickness is at $0.7-5.7 \mathrm{~m}$.

Element layer (2) - fine sand: fine sand is formed by wind, granular content is $86.5 \%$ which diameter granular is greater than $0.075 \mathrm{~mm}$, and $2.6 \%$ which diameter granular is smaller than $0.005 \mathrm{~mm}$. The soil strength is low and deformation modulus is high, expanding property caused by freezing belongs to medium. The thickness is at $1.7-6.0 \mathrm{~m}$, the bearing capacity is $100 \mathrm{kPa}$, and deformation modulus is 3.0 Mpa.

Element layer (3) - fine sand: The fine sand is formed by slop accumulation and well graded. The granular content is $87.3 \%$ which diameter granular is greater than $0.075 \mathrm{~mm}$, and $2.7 \%$ which diameter granular is smaller than $0.005 \mathrm{~mm}$. The thickness is at $1.1-10.3 \mathrm{~m}$, the bearing capacity is $160 \mathrm{kPa}$, and deformation modulus is $6.5 \mathrm{Mpa}$.

Element layer (4)-filt-fine sand: The sand is formed by flood lashed and poorly graded. The granular content is $84.6 \%$ which diameter granular is greater than $0.075 \mathrm{~mm}$, and $2.8 \%$ which diameter granular is smaller than $0.005 \mathrm{~mm}$. The thickness is at $1.6-7.5 \mathrm{~m}$, the average thickness is $5.0 \mathrm{~m}$, the bearing capacity is $165 \mathrm{kPa}$, and deformation modulus is $7.0 \mathrm{Mpa}$.

Element layer (5)-fine sand: The sand is formed by flood lashed and well graded. The granular content is $89.6 \%$ which diameter granular is greater than $0.075 \mathrm{~mm}$, and $2.6 \%$ which diameter granular is smaller than $0.005 \mathrm{~mm}$. The thickness is at $10.9-17.4 \mathrm{~m}$, the average thickness is $14.7 \mathrm{~m}$, the bearing capacity is $200 \mathrm{kPa}$, and deformation modulus is $16.0 \mathrm{Mpa}$.

\subsection{Construction Design Parameters}

The project design requires the bearing capacity of reinforcement is not smaller than $250 \mathrm{kPa}$. According to the survey report, bearing capacity of fine sand layer (3) and filt-fine sand layer (4) is respectively $160 \mathrm{kPa}$ and 165 $\mathrm{kPa}$, which satisfied the design requirement revised by depth. Backfill soil layer (1) and fine sand layer (2) are treated by dynamic compaction.

Rammer diameter is $2.4 \mathrm{~m}$, Rammer weight is $35.2 \mathrm{t}$. The maximum depth of treating is 10 . The heavy rammer of $6000 \mathrm{kN} \cdot \mathrm{m}$ energy-level is made use of in first and second times. Rammer points are arranged by square 
with spacing $6 \times 6 \mathrm{~m}$. The average settlement of the final two blow is not greater $100 \mathrm{~mm}$. Full rammed energy is $2000 \mathrm{kN} \cdot \mathrm{m}$ with two times, lapping joint of rammer print between rammer points is not smaller 1/4 [JGJ792002]. The project design requires the bearing capacity of reinforcement is not smaller than $250 \mathrm{kPa}$. According to the survey report, bearing capacity of fine sand layer (3) and filt-fine sand layer (4) is respectively $160 \mathrm{kPa}$ and $165 \mathrm{kPa}$, which satisfied the design requirement revised by depth. Backfill soil layer (1) and fine sand layer (2) are treated by dynamic compaction.

Rammer diameter is $2.4 \mathrm{~m}$, Rammer weight is $35.2 \mathrm{t}$. The maximum depth of treating is 10 . The heavy rammer of $6000 \mathrm{kN} \cdot \mathrm{m}$ energy-level is made use of in first and second times. Rammer points are arranged by square with spacing $6 \times 6 \mathrm{~m}$. The average settlement of the final two blow is not greater $100 \mathrm{~mm}$. Full rammed energy is $2000 \mathrm{kN} \cdot \mathrm{m}$ with two times, lapping joint of rammer print between rammer points is not less than the $1 / 4$ of the diameter of the tamping hammer [8].

\section{Measuring of Dynamic Compaction in Field}

\subsection{Field Measuring Purpose}

Through the field measuring of dynamic response caused by reinforcing wind-blown sand ground using dynamic compaction method, the dynamic characteristics and dynamic response are studied in order to evaluate the reinforcement effect and effective reinforcement depth.

\subsection{Measuring Point Arrangement in Site}

The typical location is selected to arrange acceleration sensors along vertical direction at measuring zone, which is separately $2 \mathrm{~m}, 4 \mathrm{~m}, 6 \mathrm{~m}, 9 \mathrm{~m}$, and $13 \mathrm{~m}$. There is an acceleration sensor in horizontal and vertical direction, as shown in Figure 1. According to the energy of dynamic compaction method, measurement range of the aceleration sensors is $50 \mathrm{~g}$ and $30 \mathrm{~g}$, which is made in Qinhuangdao science and technology limited company. Signal gathering system G01USB32 is made in engineering mechanics research institute of earthquake bureau.

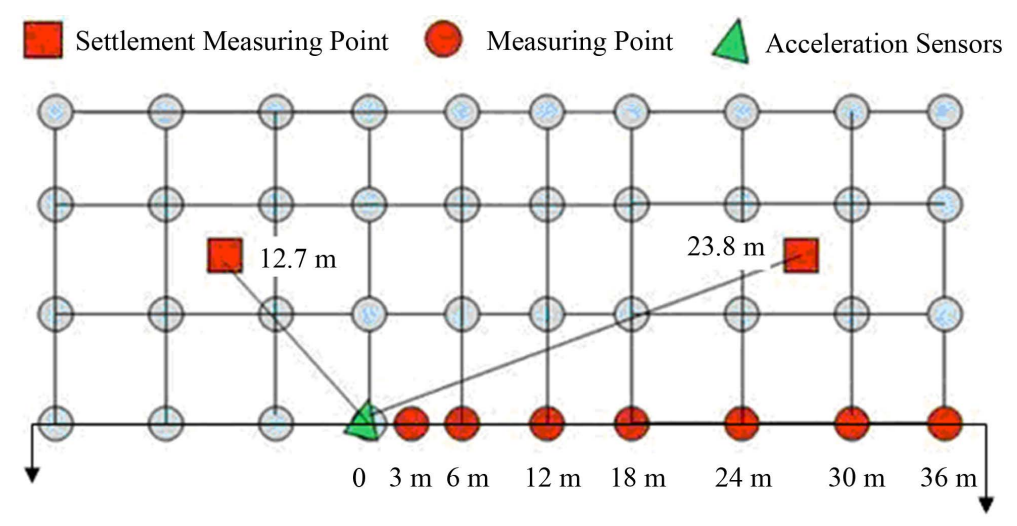

(a)

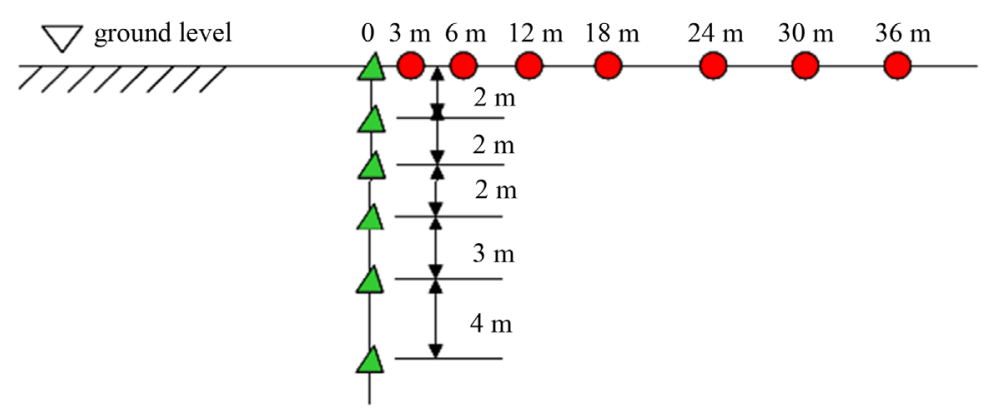

(b)

Figure 1. Arrangement scheme of measuring point of $6000 \mathrm{kN} \cdot \mathrm{m}$ energy-level.

(a) Plane figure; (b) Profile figure. 


\section{Dynamic Measuring Results Analyses of Dynamic Compaction}

\subsection{Vibration Acting Time Caused by Dynamic Compaction}

When energy level is $6000 \mathrm{kN} \cdot \mathrm{m}$, acceleration change curves with time at typical rammer point are as shown in Figures 2-5. Acceleration curve form has the similar form as the exploding vibration. The acting time of Vertical vibration is at $0.349-2.096 \mathrm{Sec}$, and that of horizontal vibration is $0.204-1.02$ Sec. Generally the Vertical vibration acting time is longer than the horizontal vibration time in the same measuring point. Vibration acting time depends on the distance between rammer point and measuring point, soil properties. When the distance between rammer point and measuring point is constant, the vibration acting time along the vertical distributing point is nearer. The Vertical average vibration acting time increases obviously with distance increasing, and the horizontal average vibration time does hardly change.

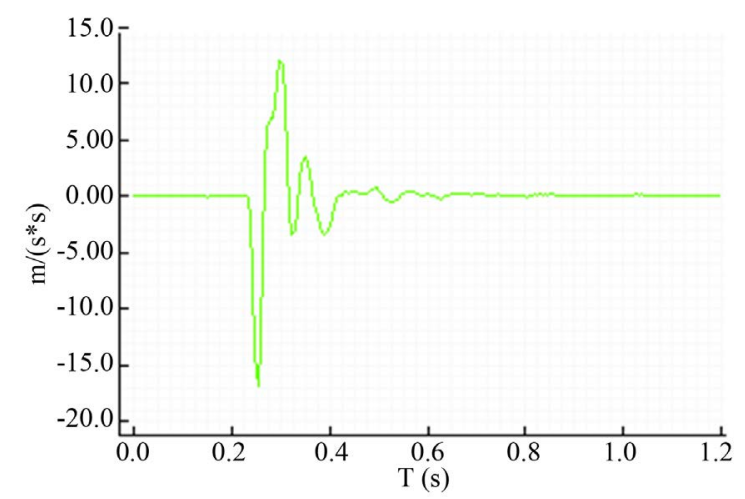

Figure 2. $a_{x} \sim t$ curve $(x=3 \mathrm{~m}, z=6 \mathrm{~m})$.

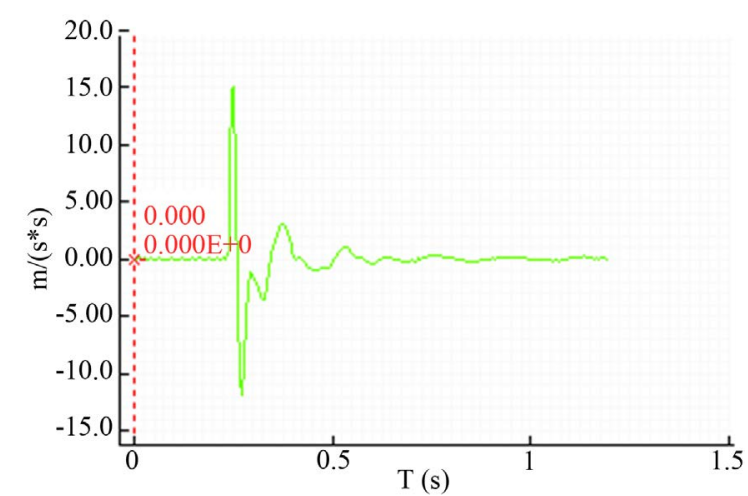

Figure 3. $a_{z} \sim t$ curve $(x=3 \mathrm{~m}, z=6 \mathrm{~m})$.

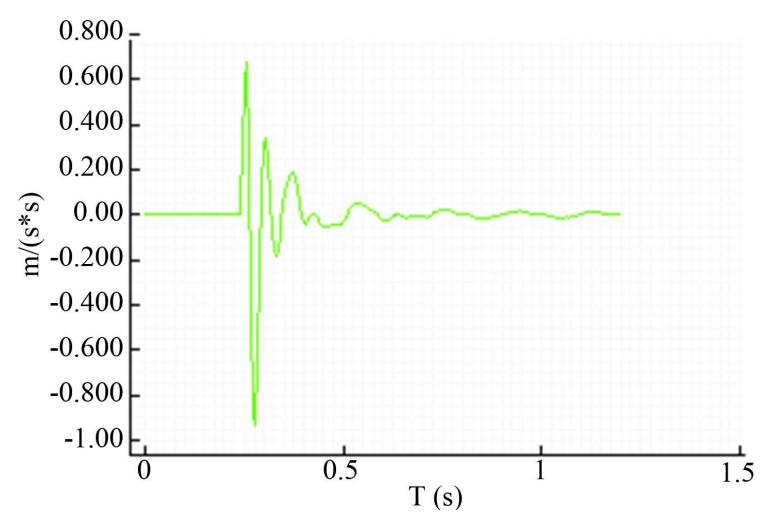

Figure 4. $a_{x} \sim t$ curve $(x=3 \mathrm{~m}, z=9 \mathrm{~m})$. 


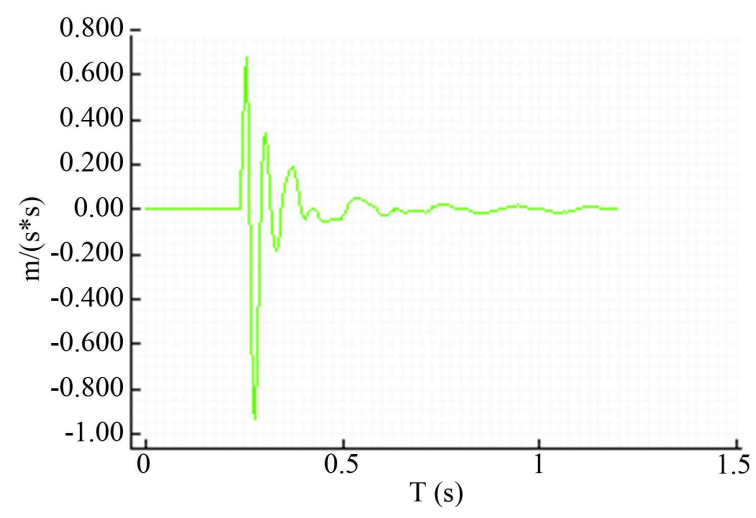

Figure 5. $a_{\mathrm{z}} \sim t$ curve $(x=3 \mathrm{~m}, \mathrm{z}=9 \mathrm{~m})$.

\subsection{The Main Frequency of Vibration}

The measuring results show that main frequency of vertical vibration is at $5.10-24.90 \mathrm{~Hz}$ in No. 1 blow and at $4.60-23.94 \mathrm{~Hz}$ in No. 2 blow. The main frequency of horizontal vibration is $5.10-24.45 \mathrm{~Hz}$ in No. 1 blow, and at $4.60-24.20 \mathrm{~Hz}$ in No. 2 blow. After the No. 1 blow, the main frequency changes because of variation of soil properties. The main frequency depends on the soil properties between the hammer point and measuring point.

\subsection{Peak Acceleration Results}

Figure 6 and Figure 7 are respectively horizontal and vertical peak acceleration color map in plane $x z$ plane. As shown in Figure 7, the horizontal peak acceleration $a_{x \max }$ is at $47.4 \mathrm{~g}-51.1 \mathrm{~g}$, when $z$ is at $2-6 \mathrm{~m}$, while is near $1.9 \mathrm{~g}$ or so when $z$ is at $9-13 \mathrm{~m}$. At $z=4 \mathrm{~m}$ and $0 \leq x \leq 36 \mathrm{~m}$, the horizontal peak acceleration of measuring point arrives maximum, and $\left.a_{x \max }\right|_{z=4 \mathrm{~m}, 6 \leq x \leq 36 \mathrm{~m}}=4.09-4.25 \mathrm{~g}$, which is larger than that of other meas ureing point in the same hammer point. As shown in Figure 8, $a_{z \max }$ is equal to $51 \mathrm{~g}$ at measuring point $(x=0$ $\mathrm{m}, z=2 \mathrm{~m}$ ), maximum point is at $z=6 \mathrm{~m}$, and $a_{z \max }=45.2 \mathrm{~g} . a_{z \max }$ changes very mall and is near $1.8 \mathrm{~g}$ when $z>6 \mathrm{~m}$.

Figure 8 and Figure 9 are respectively horizontal and vertical peak acceleration attenuation curve with the horizontal distance. The peak acceleration attenuates rapidly in horizontal direction. The influence is remarkable within $6 \mathrm{~m}$, that is $x / R<2.6$. The vertical peak acceleration is remarkable within $z<9 \mathrm{~m}$, and is near constant at $z=9-13 \mathrm{~m}$. According to ii-site survey report, backfill soil thickness is $7-10 \mathrm{~m}$.

\subsection{Treating Effective of Dynamic Compaction}

Figure 10 and Figure 11 are the color contour of peak acceleration in $x z$ plane when energy level is $6000 \mathrm{kN} \cdot \mathrm{m}$. When hammer beating energy is $6000 \mathrm{kN} \cdot \mathrm{m}$, measuring results show that the effective reinforcement depth arrives $13 \mathrm{~m}$ for wind-blown sand peak acceleration is $1.8 \mathrm{~g}$ or so. Horizontal reinforcement range is $x / R<2.6$, vertical reinforcement range is $z / R<5.7$.

\section{Conclusions}

1) The vibration of wind-blown sand caused by dynamic compaction has the similar form as the exploding vibration, and vibration acting time is very short. Generally the Vertical vibration acting time is larger than the horizontal vibration time in the same measuring point. Vibration acting time depends on the distance between rammer point and measuring point, soil properties. The Vertical average vibration acting time increases obviously with distance increasing, and the horizontal average vibration time does hardly change.

2) The measuring results show that main frequency of vibration is at $4.60-24.90 \mathrm{~Hz}$. The main frequency depends on the soil properties between the hammer point and measuring point.

3) The peak acceleration and peak velocity space distribution are similar. The maximum of horizontal acceleration peak is close to vertical velocity peak, and is near to $51 \mathrm{~g}$ under rammer. The maximum of horizontal velocity peak is close to vertical velocity peak, and is near to $54 \mathrm{~m} / \mathrm{s}$ under rammer. The peak acceleration and 


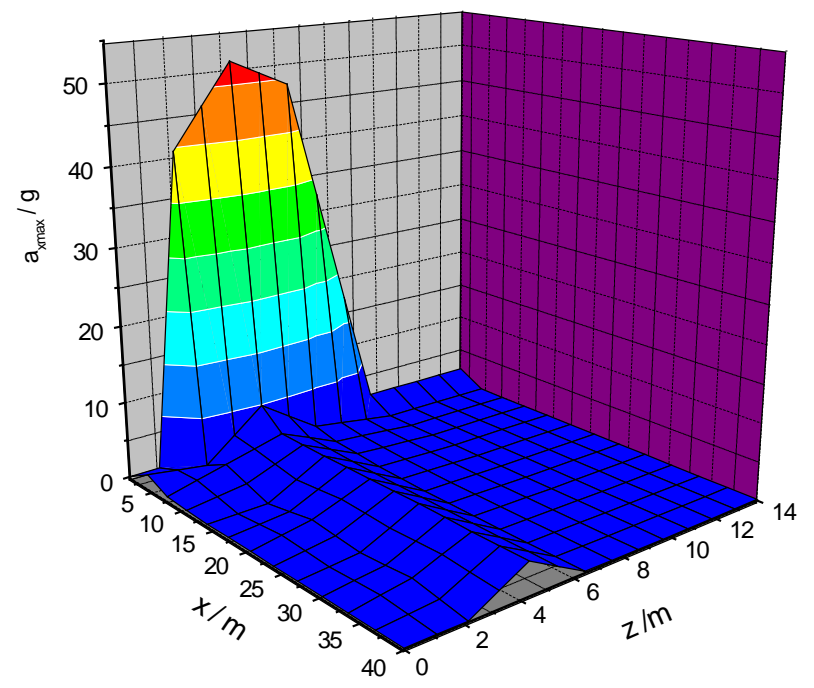

Figure 6. $a_{x \max }$ color map in $x z$ plane (No. 1).

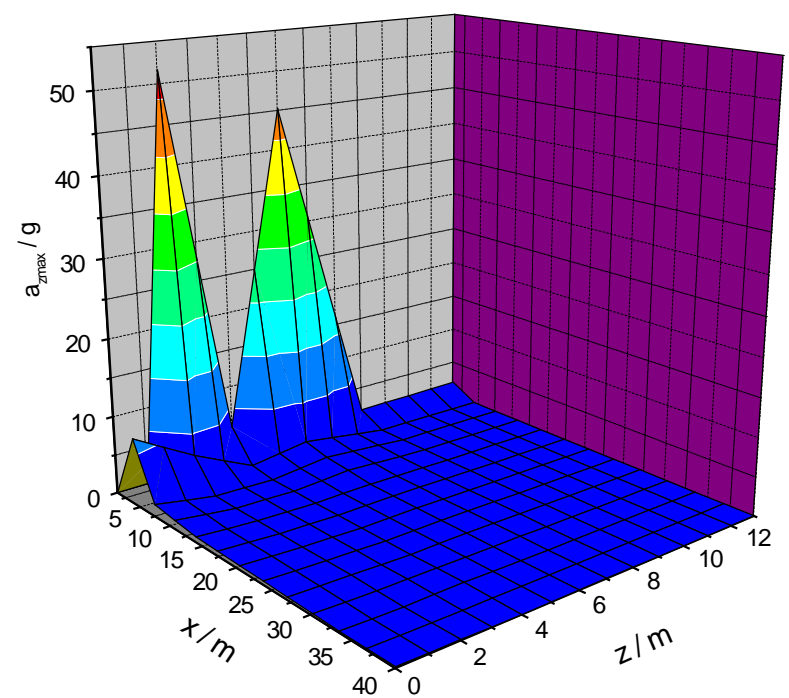

Figure 7. $a_{z \max }$ color map in $x z$ plane (No. 1 ).

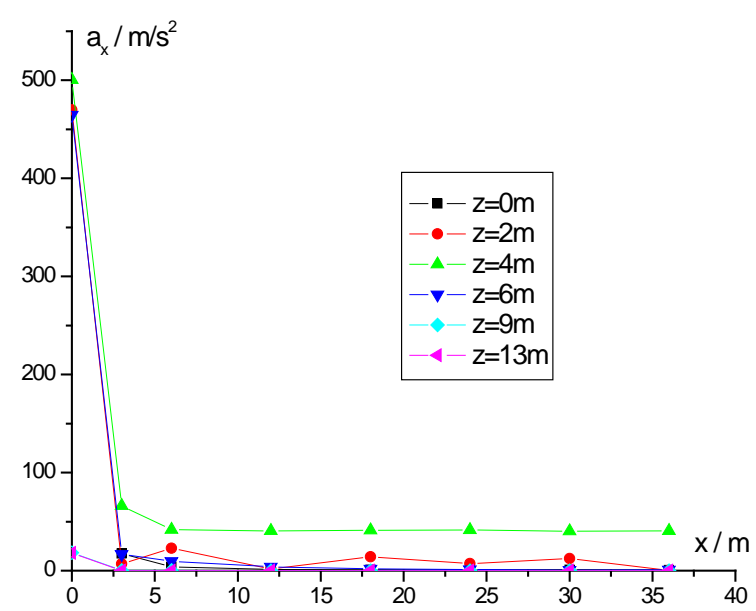

Figure 8. $a_{x \max } \sim x$ relation curve. 


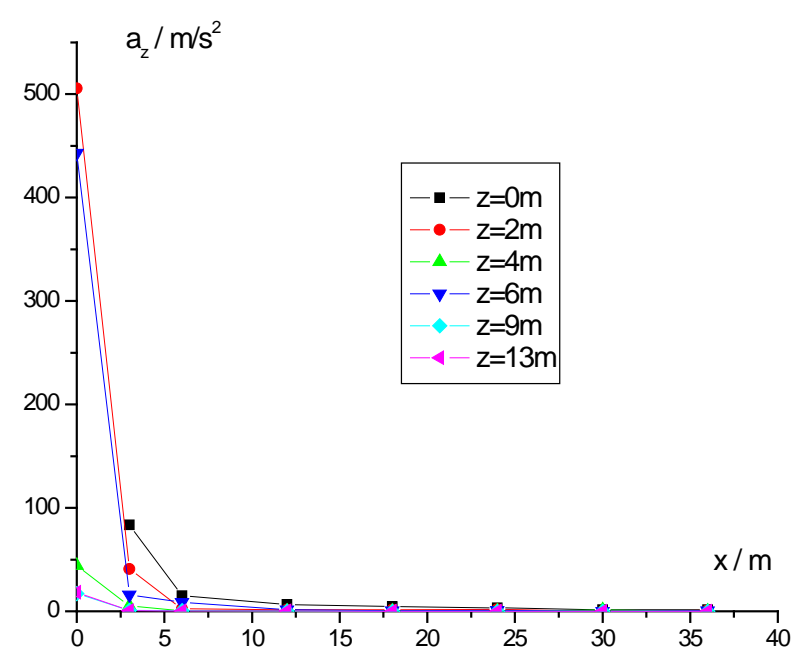

Figure 9. $a_{\mathrm{zmax}} \sim x$ relation curve.

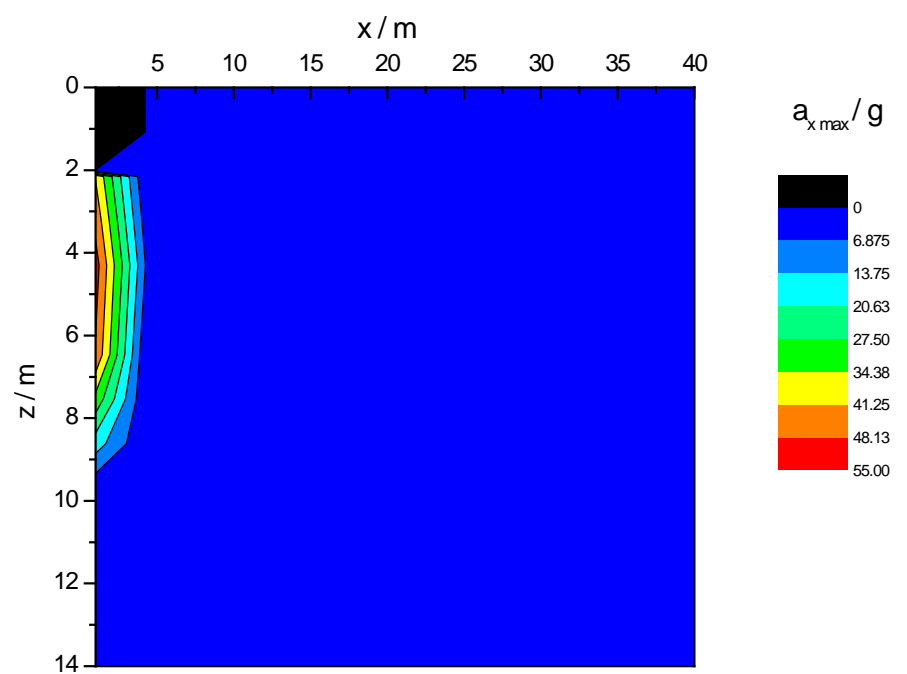

Figure 10. $a_{x \max }$ color contour in $x z$ plane (No. 1).

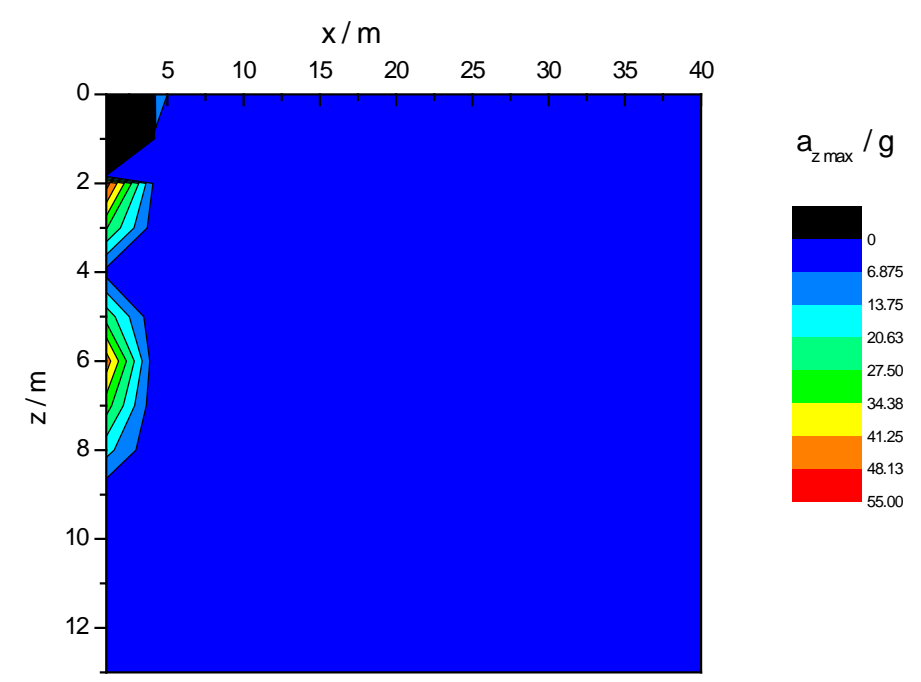

Figure 11. $a_{z \max }$ color contour in $x z$ plane (No. 1). 
velocity are rapidly attenuated in horizontal and vertical direction, but the vertical peak acceleration and peak velocity are slowly attenuated in horizontal direction.

4) When hammer beating energy is $6000 \mathrm{kN} \cdot \mathrm{m}$, the color contour shape of peak acceleration is similar to peak velocity, the effective reinforcement depth arrives $13 \mathrm{~m}$ for wind-blown wind, peak acceleration is $1.8 \mathrm{~g}$ or so, and peak velocity is $2.1 \mathrm{~m} / \mathrm{s}$ or so. Horizontal reinforcement range is $x / R<2.6$, and vertical reinforcement range is $z / R<5.7$.

\section{Acknowledgements}

This work was supported in part by Hebei Province Science and Technology Research and Development under Grant (No. 11217182).

\section{References}

[1] Liu, D.F. (2004) Discuss about Aeolian Sand Engineering Properties. West-China Exploration Engineering, 9, 31-34.

[2] Wang, J., Ren, B.Z. and Ma, Y.P. (1995) Discuss about the Reinforcement Method of Aeolian Sand. Hydrogeology and Engineering Geology, 1, 57-59.

[3] Wang, J. (2005) Impact Analysis of Sand Ground Reinforcement Using High Energy Level Dynamic Compaction. China Mining Magazine, 14, 82-85.

[4] Sun, B. (2012) Application of Dynamic Compaction Method in Processing the Foundation of Gravelly Soil. Shipbuilding of China, 53, 254-258.

[5] He, C.-M., Zou, J.-F. and Li, L. (2007) Field Tests on Measurement of Dynamic Stress of Dynamic Compaction. Chinese Journal of Geotechnical Engineering, 29, 628-632.

[6] Yin, J. and Zhang, L.-T. (2009) Test and Measurement of the Vibration Induced by Heavy Foundation and Anti-Vibration Measure. Journal of Railway Engineering Society, 127, 17-20.

[7] Zhan, J.-L., Shui, W.-H. and Liang, Y.-H. (2009) Experimental Research on Treating Desert Soil Ground with Dynamic Compation. Rock and Soil Mechanics, 30, 489-492.

[8] (2012) JGJ79-2012 Technical Code for Ground Treatment of Buildings. China Architecture Industry Press, Beijing. 
Scientific Research Publishing (SCIRP) is one of the largest Open Access journal publishers. It is currently publishing more than 200 open access, online, peer-reviewed journals covering a wide range of academic disciplines. SCIRP serves the worldwide academic communities and contributes to the progress and application of science with its publication.

Other selected journals from SCIRP are listed as below. Submit your manuscript to us via either submit@scirp.org or Online Submission Portal.
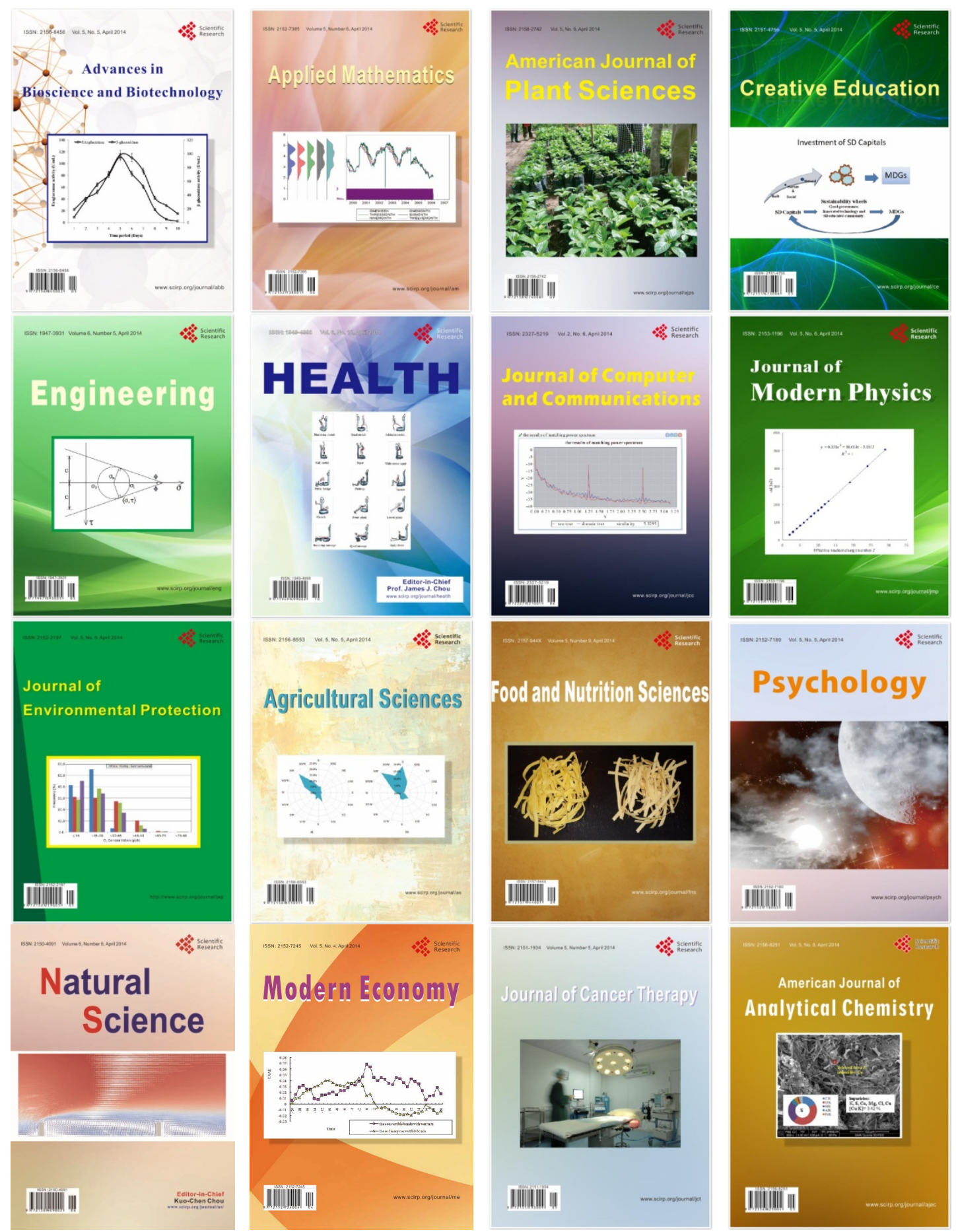